\title{
Erratum to: Mycorrhizal colonization and distribution of arbuscular mycorrhizal fungi associated with Michelia champaca L. under plantation system in northeast India
}

\author{
Das Panna $•$ Kayang Highland \\ (C) Northeast Forestry University and Springer-Verlag Berlin Heidelberg 2010 \\ Erratum to: Journal of Forestry Research (2010) 21(2): 137-142 \\ DOI 10.1007/s11676-010-0022-2
}

The original version of this article unfortunately contained six mistakes.

In Abstract section on page 137:

1. Results showed that AMF colonization was significantly higher than dark septate endophyte colonization $(p>0.05)$.

The correct writing should be:

Results showed that AMF colonization was significantly higher than dark septate endophyte colonization $(p<0.05)$.

2. Spore density varied significantly in all the sites $(p>0.05)$.

The correct writing should be:

Spore density varied significantly in all the sites $(p<0.05)$.

In "Mycorrhizal colonization" subtitle of Results section on page 139:

3. However, AMF colonization was significantly higher ( $p>0.05)$ than DSE (Fig. 3).

The correct writing should be:

However, AMF colonization was significantly higher $(p<0.05)$ than DSE (Fig. 3).

4. Spore density differed statistically in all the sites $(p>0.05)$.

The correct writing should be:

Spore density differed statistically in all the sites $(p<0.05)$.

5. No significant correlation was found between mycorrhizal colonization, soil properties, $\mathrm{CBH}$ and $\mathrm{H}(p>0.05)$.

The correct writing should be:

No significant correlation was found between mycorrhizal colonization, soil properties, $\mathrm{CBH}$ and $\mathrm{H}(p<0.05)$

6 . Tukey test showing different alphabetical letters varies significantly $(p>0.05)$.

The correct writing should be:

Tukey test showing different alphabetical letters varies significantly $(p<0.05)$.

The online version of the original article can be found at

http://dx.doi.org/10.1007/s11676-010-0022-2

Das Panna $\bullet$ Kayang Highland $(-2)$

Microbial Ecology Laboratory, Department of Botany, North Eastern

Hill University, Shillong-793 022, India. Email: hkayang@yahoo.com

Das Panna

Microbiology Laboratory, Department of Botany, Tripura University,

Suryamaninagar- 799 130, Tripura, India

Responsible editor: Hu Yanbo 